\title{
IDENTIFICATION OF METABOLIC INDICATORS FOR CARDIOVASCULAR RISK IN SCHOOLCHILDREN
}

\author{
Mónica López Palafox ${ }^{1}$, Luis Celis², María del Socorro Camarillo Romero ${ }^{1}$, \\ Amparo Russi ${ }^{3}$, Araceli Consuelo Hinojosa Juárez ${ }^{1}$,Carmen Cecilia Almonacid Urrego ${ }^{4,5}$, \\ Eneida Camarillo Romero ${ }^{1}$, Hugo Mendieta Zerón ${ }^{1,5}$ \\ ${ }^{1}$ Autonomous University of the State of México (UAEMex), Faculty of Medicine, Toluca, Mexico \\ ${ }^{2}$ Universidad de la Sabana, Cundinamarca, Colombia \\ ${ }^{3}$ Clínica CMC Country Medical Center, Colombia \\ ${ }^{4}$ Universidad Colegio Mayor de Cundinamarca (UCMC), Bogotá, Colombia \\ ${ }^{5}$ ASociación CIentífica LAtina A.C. (ASCILA), Toluca, Mexico
}

\begin{abstract}
Objective. CardioVascular Disease (CVD) is one of the most important causes of death worldwide affecting people at younger ages every year. The purpose of this study was to identify the metabolic indicators for cardiovascular risk factors in primary school students from Mexico and Colombia.

Methods. A clinical, prospective, cross-sectional and comparative study was conducted in Mexico and Colombia to contrast anthropometric measurements, biochemical and dietetic determinations and physical activity.

Results. The Waist-Hip Ratio (WHR) and the Waist-to-Height Ratio (WtHR) showed significant differences ( $\mathrm{p} \leq 0.001$ ) between Mexico and Colombia $(0.8 \pm 0.1$ versus $0.5 \pm 0.1)$ and $(0.4 \pm 0.06$ vs. $0.78 \pm 0.04)$ respectively. The Automatic Linear Modeling showed that the main predictors for cholesterol levels were WtHR, MonoUnsaturated Fatty Acids (MUFA) and lipids ingestion. For glucose there were four main predictors: WHR, carbohydrates, MUFA and Saturated Fatty Acids (SFA). For triglycerides the pedictors were Products of Animal Origin (PAO), BMI, waist circumference, lipids and cholesterol ingestion and Mean Arterial Pressure (MAP). The Weight Estimation tests weighted per gender showed that for glucose levels the main determinants were carbohydrates, MUFA and oils; for cholesterol these were MUFA, PUFA and oils; and for LDL the significant variables were proteins, SFA, PAO and sugars; and last, for triglycerides the main variables were BMI, cholesterol and vegetables.

Conclusions. Mexico has higher values in almost all items of cardiovascular risk in children, but both countries have significant percentages of obesity and the population free of cardiovascular risk is minimal.
\end{abstract}

Key words: cardiovascular risk, children, cholesterol, Colombia, glucose, Mexico, triglycerides.

\section{INTRODUCTION}

Cardiometabolic risk is that which carries a predisposition to a chronic disease, such as atherosclerosis and diabetes; it can comprise a single factor or can be associated with Metabolic Syndrome (MetS) $[1,2]$. Despite its being a topic widely studied in adults, in pediatric population it has not had the same impact [2]. Fortunately, there has been a major effort currently in the prevention of CardioVascular Disease (CVD) in childhood. Indeed, the adoption of novel indexes, apart from the traditional ones, has been proof of this growing interest. However, the identification of a high-risk subject when symptoms are absent remains a challenge [3].
In addition to the new markers for CVD, such as like homocysteine and fibrinogen, there are some other anthropometric indices with greater specificity for children, such as waist-to-height index (WtHR), which has completely replaced the Waist-Hip Ratio (WHR). This is a very useful tool to know the adiposity, which is one of the first steps in the atherosclerotic process [4].

Previous studies have confirmed that anthropometric indicators are associated with selected cardiometabolic risk factors in early childhood [5] but measurement of their risk factors beyond Body Mass Index (BMI) and waist circumference may provide evidence in defining cardiometabolic risk in early childhood [6].

The purpose of this study was to identify the main metabolic indicators for cardiovascular risk factors in primary school students from Mexico and Colombia.

Corresponding author: Hugo Mendieta Zerón, Autonomous University of the State of México (UAEMex), Faculty of Medicine, Felipe Villanueva Sur 1209, Col. Rancho Dolores, C.P. 50170 Toluca, Edo. de México, México. Phone/Fax: (+52) (722) 219 4122, ext. 157; e-mail: drmendietaz@yahoo.com 


\section{MATERIALS AND METHODS}

This clinical, prospective, and comparative study was carried out in the cities of Toluca, Mexico, and Bogota, Colombia, from September 2015 to August 2016. Children aged 6-13 years from Primary Schools "Horacio Zuñiga" (Toluca) and "Venustiano Carranza" (San Mateo Atenco) both in Mexico, and "Gimnasio Yacard" (Bogota) in Colombia were matched by gender and age. We excluded all children whose parents did not authorize their participation by signing informed consent or those who did not accept to participate with informed assent. Children with phobias to venous sampling were excluded, and nonviable samples were not included in the final analysis.

Taking into account a previous work that showed that for Colombian children only $13 \%$ had an altered metabolic parameter [7] while in the population of Mexican children this percentage was $45 \%$; accepting an alpha risk of 0.05 and a beta risk of 0.2 in a bilateral test, 30 subjects per group were required to find a statistically significant difference in proportion in the presence of an SM parameter.

Clinical and sociodemographic data were obtained from the child's clinical history. Food-consumption habits were evaluated with the 3-day reminder as gold standard ( 2 days from Monday to Friday, and 1 day for the weekend). All of the nutrients were calculated on Nutrimind ${ }^{\circledR}$ nutritional software, and equivalents per day were measured based on the groups from the Mexican model "Plato del Buen Comer". Physical activity was evaluated with the short form of the International Physical Activity Questionnaire (IPAQ), which has three levels: 1) Low level (no physical activity); 2) Moderate (3 or more days with intense activity, taking into consideration intense activity or at least $30 \mathrm{~min}$ ), and 3) Intense level (intense activity 3 days per week, seven, or more days with any combination).

Weight and height were measured to one decimal place while wearing the child was wearing light clothing and without shoes, using a calibrated digital scale (Microlife AG 9435 model) and a stadiometer (Seca 213 model). Waist Circumference (WC) and Hip Circumference (HC) were measured as anthropometric indicators for cardiovascular risk utilizing a fiberglass tape measure to the nearest $0.1 \mathrm{~cm}$, and for $\mathrm{WC}$ taking the midpoint between the last rib and the iliac crest, considering the average of both measures. The WtHR was determined by dividing WC $(\mathrm{cm})$ by height $(\mathrm{cm})$ [5]. BMI was calculated as weight in kilograms divided by height in meters squared $\left(\mathrm{kg} / \mathrm{m}^{2}\right)$.

Blood Pressure (BP; mmHg) was checked by auscultation employing a pediatric sphygmomanometer and an appropriately sized cuff. Measurement was performed with the child at rest and by a single experienced professional. Percentiles for systolic and diastolic pressure by age and gender were determined [8]
Blood samples were collected to measure glucose $(\mathrm{mg} / \mathrm{dL})$, Total Cholesterol (TC) (mg/dL), HighDensity Lipoprotein cholesterol (HDLc) $(\mathrm{mg} / \mathrm{dL}$ ), Low-Density Lipoprotein cholesterol (LDLc) (mg/ $\mathrm{dL}$ ), and TriGlycerides (TG) (mg/dL) (RX Monza CH200 Randox for Mexico and Mindray BS200 Annar Diagnostics for Colombia), according to standardized procedures. The TG-HDLc ratio (TG-HDLc) was calculated as a possible risk iondicator of organ damage. All measurements followed standardized procedures according to International Federation of Clinical Chemistry and Laboratory Medicine (IFCC).

Malnutrition (underweight, overweight, and obesity) was defined according to the BMI percentiles of the World Health Organization (WHO) [9]. Cutoff points were defined with percentiles for WC, for the waist/hip index ( 0.85 for girls and 0.94 for boys) [10] and for WtHR equations from Marrodán et al. [4] High BP was defined as BP $>95^{\text {th }}$ percentile according to the National High Blood Pressure Education Program Working Group on Children and Adolescents (NHBPEP) [6].

Impaired Fasting Glucose (IFG) was defined by a value of fasting plasma glucose of $>100 \mathrm{mg} / \mathrm{dL}$ according to the recommendations of the American Diabetes Association (ADA) [11]; for lipid profile and MetS, we utilized Adult Treatment Panel (ATP) III criteria as follows: TC $<170 \mathrm{mg} / \mathrm{dL}$; LDLc $<110 \mathrm{mg} /$ $\mathrm{dL}$; HDLc $>45 \mathrm{mg} / \mathrm{dL}$, TG from $0-9$ years $<75 \mathrm{mg} /$ $\mathrm{dL}$, and TG from 10-19 years, $<90 \mathrm{mg} / \mathrm{dL}$. For TgHDLc, a cut-off value of $<2.2$ was obtained [12].

We utilized the SPSS ver. 22 statistical software package (IBM Corp., Armonk, NY, USA). Continuous data were expressed as means \pm Standard Deviation (SD). Student $t$ test or Mann-Whitney $U$ test were used depending whether the variables were or were not normally distributed when doing comparisons per Country or per gender. The degree of association between variables was evaluated using the Pearson correlation. A $P$ value of $\leq 0.05$ was considered statistically significant in all tests. The Multivariate General Linear Model, Automatic Linear Modeling and Weight Estimation were used to analyze several variables to predict glucose, cholesterol and triglycerides levels.

The study was approved by the Ethics and Research Committees of the Medical Sciences Research Center (CICMED), Autonomous University of the State of Mexico (UAEMex), Toluca, Mexico (code: 2015/10), Universidad Antonio Nariño, Bogota, Colombia (Acta No. 001 of 2015, clause z), and Universidad de la Sabana, Bogota, Colombia (Act 50-2015). All of the procedures were conducted in accordance with the Declaration of Helsinki and the General Health Law of Mexico. Informed consent was obtained from the children's parents and informed assent, from the students. 


\section{RESULTS}

Ninety students were included in the study: 57 from Mexico (22 boys and 35 girls), and 33 from Colombia (21 boys and 12 girls). Anthropometric and clinical characteristics are presented in Table 1. From the obtained data, there are three significant aspects between both studied groups. First, weight was higher in Mexican children $(37.2 \pm 12.5 \mathrm{~kg})$ than in Colombian children $(34.3 \pm 8.9 \mathrm{~kg})$. Second, BMI was also higher in Mexican young population ( $19 \pm 5.5 \mathrm{vs}$. $18.4 \pm 3.07)$. Third, in relation to both, the WHR and the WtHR, there were significant differences $(\mathrm{p} \leq 0.001)$ between Mexico and Colombia $(0.8 \pm 0.1$ versus $0.5 \pm$ $0.1)$ and $(0.4 \pm 0.06$ vs. $0.78 \pm 0.04)$.

Table 1. Anthropometric and clinical characteristics of the population (mean \pm Standard Deviation - SD)

\begin{tabular}{|c|c|c|c|c|c|c|c|}
\hline \multirow{2}{*}{ Variables } & \multicolumn{3}{|c|}{ Mexican children } & \multicolumn{3}{|c|}{ Colombian children } & \multirow[t]{2}{*}{$p$} \\
\hline & Mean & SD & Range & Mean & SD & Range & \\
\hline Age (years) & 10.6 & 1.31 & $6.9-13.4$ & 9.1 & 2.1 & $6-12.7$ & 0.333 \\
\hline Height (cm) & 141 & 9.5 & $108.5-160$ & 135.9 & 12 & $119.9-163.3$ & 0.065 \\
\hline Weight (kg) & 37.2 & 12.5 & $18.2-80.9$ & 34.3 & 8.9 & $21.5-51.5$ & 0.182 \\
\hline BMI $\left(\mathrm{kg} / \mathrm{m}^{2}\right)$ & 19 & 5.5 & $12-38.7$ & 18.4 & 3.0 & $13.2-24.5$ & 0.525 \\
\hline Waist (cm) & 68.6 & 12.1 & $53-113$ & 65 & 10.2 & $51-97$ & 0.523 \\
\hline Hip $(\mathrm{cm})$ & 77.5 & 10.3 & $60-116$ & 83 & 11.1 & $64.5-110.1$ & 0.51 \\
\hline WHR & 0.8 & 0.1 & $0.14-1-07$ & 0.5 & 0.1 & $0.4-0.8$ & $\leq 0.001$ \\
\hline WtHR & 0.4 & 0.06 & $0.4-0.7$ & 0.78 & 0.04 & $0.73-1$ & $\leq 0.001$ \\
\hline SBP (mmHg) & 96.9 & 13.5 & $65-130$ & 114 & 21.2 & $78-171$ & $\leq 0.001$ \\
\hline DBP (mmHg) & 69 & 9.8 & $40-90$ & 67.2 & 12.3 & $26-88$ & 0.518 \\
\hline Physical activity $(\mathrm{m} / \mathrm{d} / \mathrm{w})$ & 1,510 & 1832.5 & $200-11,300$ & $2,507.1$ & 1,847 & $720-8760$ & 0.001 \\
\hline
\end{tabular}

BMI: Body Mass Index; DBP: Diastolic Blood Pressure; SBP: Systolic Blood Pressure; WHR: Waist-Hip Ratio; WtHR: Waist-to-Height Ratio; $\mathrm{m} / \mathrm{d} / \mathrm{w}$ : minutes per day per week.

According to our results, for the nutritional diagnosis, $10 \%$ of children were found with obesity, $68 \%$ with malnutrition and $8.7 \%$ with overweight in Mexico, while in Colombia these same percentages were $24.24 \%, 12.12 \%$ and $23.1 \%$. To be more emphatic, while in Colombia $18 \%$ of children were eutrophic, in Mexico, this percentage was only $13.3 \%$.

Regarding the biochemical parameters (Table 2), for Mexican population, we found that $3.5 \%$ of the children registered high glucose concentrations $(>100$ $\mathrm{mg} / \mathrm{dL}$ ), and regarding cholesterol, $31.5 \%$ of the population was found with numbers $>170 \mathrm{mg} / \mathrm{dL}, 28 \%$ with numbers $<45 \mathrm{mg} / \mathrm{dL}$ for HDLc, $50.8 \%$ exhibited numbers above desirable limits for TG, and $71.9 \%$ demonstrated an altered high TG/lipoprotein index. The results obtained for the Colombian population for these were $1.7,42.4,0,57.5$, and $45.4 \%$, respectively. When comparing by country, it is possible to observe that Mexico has higher numbers in virtually all items except total cholesterol.

Table 2. Biochemical data (mean \pm Standard Deviation $[\mathrm{SD}]$ )

\begin{tabular}{lccccccc}
\hline & \multicolumn{3}{c}{ Mexican children } & \multicolumn{3}{c}{ Colombian children } \\
& Mean & SD & Range & Mean & SD & Range & $p$ \\
\hline Glucose (mg/dL) & 90.1 & 10.1 & $73-112$ & 78.2 & 10 & $51-106$ & 0.518 \\
HDLc (mg/dL) & 43.1 & 7.9 & $24-56.2$ & 60.5 & 10.3 & $43-78$ & 0.158 \\
LDLc (mg/dL) & 94.6 & 21.5 & $41.8-133$ & 102.4 & 31.2 & $46.4-169.6$ & 0.155 \\
TC (mg/dL) & 161.4 & 20.4 & $103-205$ & 186.7 & 37.6 & $130-268$ & 0.082 \\
TG (mg/dL) & 126.5 & 48.8 & $48-274$ & 118.5 & 38.2 & $60-196$ & 0.023 \\
TG/HDLc index & 3.1 & 1.2 & $1.1-6.6$ & 2 & 0.8 & $0.8-4.4$ & $\leq 0.001$ \\
\hline
\end{tabular}

HDLc: High Density Lipoprotein cholesterol; LDL: Low-Density Lipoprotein cholesterol; TC: Total Cholesterol; TG: TriGlycerides; TG/HDLc: TriGlycerides/High-Density Lipoprotein cholesterol index.

Nutritional information is illustrated in Table 3. Total caloric ingestion was higher in Mexican than in Colombian children $(1,889.14 \pm 300.78$ calories vs. $1,850.9 \pm 369.6$ ), and this was similar with proteins ( $62.5 \pm 14.16$ vs. $56.33 \pm 13.46$ grams $)$. On the other hand, fat consumption was higher in Colombian than in Mexican population (71.29 \pm 23.91 vs. $66.29 \pm$ $17.58 \mathrm{~g} /$ day). The distribution of fiber was similar for both countries $(8.4 \pm 2.82$ vs. $10 \pm 4.01 \mathrm{~g} /$ day $)$. For the vitamin consumption, the same pattern was maintained with an intake below the daily recommendations for both countries. In the case of fatty acids (monounsaturated) and polyunsaturated, the higher consumption was registered in Colombian children $(26.7 \pm 5.3$ vs. $16.2 \pm 5.8 \mathrm{~g} /$ day) and $(265.4 \pm 326.1 \mathrm{vs}$. $184.8 \pm 107.0 \mathrm{~g} /$ day). For food groups and equivalents 
per day, the mean difference was between oils and fats, with an increased consumption in the Colombian group (5.24 \pm 1.77 vs. $2.21 \pm 0.92$ equivalents); the remainder of the food groups remained homogeneous.

Classification of nutritional intake and percentage of nutritional recommendation is presented in Table 4. In both countries, only two groups covered the full recommendation for protein $(100 \%)$ and dairy products $(84 \%$ in Colombia and $88 \%$ in Mexico).
For the carbohydrate group, consumption level is above the recommendation in both countries (110 and $120 \%$ for México and Colombia, respectively). The groups that were found at the lower end with a very low percentage of consumption in the Mexican group were those of fiber, vegetables, and sugars $(1.7,2$, and $5 \%$ ), while in the Colombian group, sugars make the difference with an increase of $10 \%$ on comparison with the Mexican group.

Table 3. Nutritional information (mean \pm Standard Deviation - SD)

\begin{tabular}{lcccccc}
\hline & \multicolumn{3}{c}{ Mexican children } & \multicolumn{3}{c}{ Colombian children } \\
& Mean & SD & Range & Mean & SD & Range \\
\hline Energy (calories/day) & $1,889.1$ & 300.7 & $1,300-2,741$ & $1,850.9$ & 369.6 & $912-2507$ \\
Carbohydrates $(\mathrm{g})$ & 218.2 & 119.7 & $98-745$ & 240.3 & 47.1 & $115-317$ \\
Fat $(\mathrm{g})$ & 66.2 & 17.5 & $33-101$ & 71.2 & 23.9 & $16-107$ \\
Protein $(\mathrm{g})$ & 62.5 & 14.1 & $33-89$ & 56.3 & 13.4 & $17-87$ \\
Fiber $(\mathrm{g})$ & 8.4 & 2.8 & 0321 & 10.0 & 4.0 & 317 \\
Pyridoxine B6 (mg/dL) & 0.61 & 0.4 & $0-1.7$ & 0.9 & 0.3 & $0-1.7$ \\
Folic acid B9 $(\mu \mathrm{g} / \mathrm{d})$ & 115.7 & 18.9 & $50-165$ & 116.5 & 33.1 & $34-178$ \\
Cobalamin B12 $(\mu \mathrm{g} / \mathrm{d})$ & 1.41 & 0.6 & $0.5-3.6$ & 2.2 & 1.0 & $0-4.3$ \\
Dietary cholesterol $(\mu \mathrm{g} / \mathrm{d})$ & 202.1 & 69.8 & $76-380$ & 175.6 & 97.8 & $0-373$ \\
MUFA $(\mathrm{g} / \mathrm{d})$ & 16.2 & 5.8 & $04-36$ & 26.7 & 5.3 & $0-260$ \\
PUFA $(\mathrm{g} / \mathrm{d})$ & 184.8 & 107.0 & $9-541$ & 265.4 & 326.1 & $1-887$ \\
Saturated fatty acids $(\mathrm{g} / \mathrm{d})$ & 16.2 & 10.4 & 0262 & 11.3 & 9.3 & 143 \\
Animal products (eq/d) & 2.1 & 1.0 & $1-5.5$ & 1.7 & 1.0 & $0-6.3$ \\
Cereals (eq/d) & 7.4 & 1.5 & 0411 & 7.4 & 1.8 & 0312 \\
Fruits (eq/d) & 2.5 & 1.2 & $1-5.4$ & 1.9 & 1.3 & $0-5.2$ \\
Oils and fat (eq/d) & 2.2 & 0.9 & $0-5$ & 5.2 & 1.7 & 18 \\
Vegetables (eq/d) & 1.2 & 0.8 & $0-4$ & 0.4 & 0.3 & $0-1$ \\
Dairy products (eq/d) & 1.1 & 0.4 & $0.4-2.7$ & 1.2 & 0.6 & $0-2.8$ \\
Sugars (eq/d) & 5.7 & 1.5 & $1.4-9$ & 5.1 & 1.8 & $1-8.7$ \\
\hline
\end{tabular}

MUFA: MonoUnsaturated Fatty Acids; PUFA: PolyUnsaturated fatty acids.

Table 4. Classification of nutritional intake and percentage of nutritional recommendation (mean \pm Standard Deviation - SD)

\begin{tabular}{|c|c|c|c|c|c|c|c|c|}
\hline & \multicolumn{4}{|c|}{ Mexican children } & \multicolumn{4}{|c|}{ Colombian children } \\
\hline & A & I & $\leq \mathrm{RDA}$ & $>$ RDA & A & I & $\leq \mathrm{RDA}$ & $>\mathrm{RDA}$ \\
\hline Energy (calories/day) & & $\mathrm{X}$ & 19 & 81 & & $\mathrm{X}$ & 8.8 & 91.2 \\
\hline Carbohydrates (g/day) & & $\mathrm{X}$ & 0 & 100 & & $\mathrm{X}$ & 0 & 100 \\
\hline Fat (g/day) & & $\mathrm{X}$ & 7 & 93 & & $\mathrm{X}$ & 3 & 97 \\
\hline Protein (g/day) & $\mathrm{X}$ & & 100 & 0 & $\mathrm{X}$ & & 100 & 0 \\
\hline Fiber (g/day) & & $\mathrm{X}$ & 98.3 & 1.7 & & $\mathrm{X}$ & 2.2 & 97.8 \\
\hline Pyridoxine B6 (mg/dL) & & $\mathrm{X}$ & 59.7 & 40.3 & & $\mathrm{X}$ & 68.9 & 31.1 \\
\hline Folic acid B9 $(\mu \mathrm{g} / \mathrm{d})$ & & $\mathrm{X}$ & 68.1 & 31.9 & & $\mathrm{X}$ & 80 & 20 \\
\hline Cobalamin B12 $(\mu \mathrm{g} / \mathrm{d})$ & & $\mathrm{X}$ & 82 & 18 & & $\mathrm{X}$ & 75.7 & 24.3 \\
\hline Dietary cholesterol $(\mathrm{mg} / \mathrm{d})$ & & $\mathrm{X}$ & 10 & 90 & & $\mathrm{X}$ & 5 & 95 \\
\hline Animal products (eq/d) & & $\mathrm{X}$ & 28 & 72 & & $\mathrm{X}$ & 33 & 67 \\
\hline Saturated fatty acids (g/d) & & $\mathrm{X}$ & 30 & 70 & & $\mathrm{X}$ & 33 & 67 \\
\hline Cereals (eq/d) & & $\mathrm{X}$ & 22.8 & 77.2 & & $\mathrm{X}$ & 24.2 & 758 \\
\hline Fruits (eq/d) & & $\mathrm{X}$ & 5.2 & 94.8 & & $\mathrm{X}$ & 9 & 91 \\
\hline Vegetables (eq/d) & & $\mathrm{X}$ & 98 & 2 & & $\mathrm{X}$ & 97.3 & 2.7 \\
\hline Dairy products (eq/d) & $\mathrm{X}$ & & 84 & 16 & $\mathrm{X}$ & & 88 & 12 \\
\hline Oils and fat (eq/d) & & $\mathrm{X}$ & 20 & 80 & & $\mathrm{X}$ & 21.2 & 78.8 \\
\hline Sugars (eq/d) & & $\mathrm{X}$ & 5 & 95 & & $\mathrm{X}$ & 15.1 & 84.9 \\
\hline
\end{tabular}

A: Adequate; I: Inadequate, RDA: Recommended Dietary Allowance. 
The Pearson test revealed a positive relationship between WtHR and WHR for the two countries and both rates were higher for Mexican population $(0.89 \pm$ 0.07 vs. $0.78 \pm 0.04)$ and $(0.48 \pm 0.07$ vs. $0.47 \pm 0.07)$ (Table 5).

The Multivariate General Linear Model, showed that the levels of cholesterol are influenced by the WtHR ( $p=0.019)$, and glucose levels are influenced by the grams ingestion of carbohydrates $(\mathrm{p}=0.019)$,
MonoUnsaturated Fatty Acids (MUFA) $(\mathrm{p} \leq 0.001)$, and PolyUnsaturated fatty acids (PUFA) $(\mathrm{p}=0.008)$. Performing the same model but weighted by gender showed that a statistical significance was kept for the same intereactiones with the next values of $p$ : $0.045,0.021, \leq 0.001$ and 0.008 . In a third approach, weighting per Country, carbohydrates, MUFA and PUFA determined the values of glucose $(\mathrm{p}=0.017$, 0.001 and 0.013 , repectively).

Table 5. Pearson correlation between Body Mass Index (BMI) and atherogenic indices

\begin{tabular}{|l|c|c|c|c|c|c|}
\hline \multirow{2}{*}{} & \multicolumn{2}{|c|}{ Mexico } & \multicolumn{2}{c|}{ Colombia } & \multicolumn{2}{c|}{ Both countries } \\
\cline { 2 - 7 } & $r$ & $P$ & $r$ & $P$ & $r$ & $P$ \\
\hline BMI vs. WHR & 0.385 & 0.003 & 1.000 & $\leq 0.001$ & 0.999 & $\leq 0.001$ \\
\hline BMI vs. WtHR & 0.681 & $\leq 0.001$ & 1.000 & $\leq 0.001$ & 0.999 & $\leq 0.001$ \\
\hline BMI vs. TG/HDLc & 0.420 & $\leq 0.001$ & 0.002 & $\leq 0.990$ & 0.001 & 0.995 \\
\hline
\end{tabular}

BMI: Body Mass Index; TG/HDLc: triglycerides/high density lipoprotein cholesterol index, WHR: Waist Hip ratio; WtHR waist-height ratio.

Using the Automatic Linear Modeling it was obtained that the main predictor for cholesterol were WtHR, MUFA and lipids ingestion (grams/day) (Figure 1A). For glucose there were four main predictors: WHR, carbohydrates, MUFA and Saturated Fatty Acids (SFA)
(Figure 1B). Finally, for triglycerides the pedictors were Products of Animal Origin (PAO) (equivalents/day), BMI, waist circumference, lipids ingestion (grams/ day), cholesterol ingestion and Mean Arterial Pressure (MAP) (mm Hg) (Figure 1C).

\section{A}

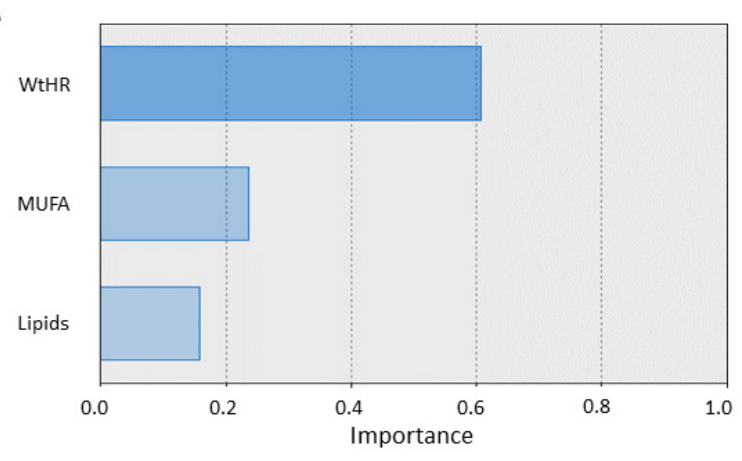

B

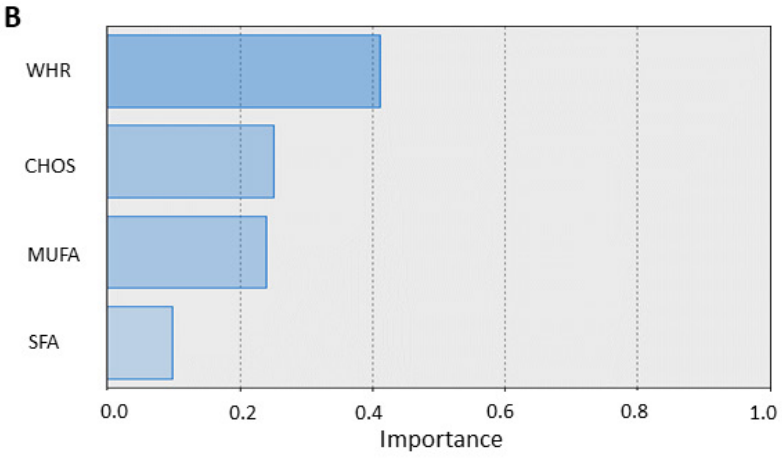

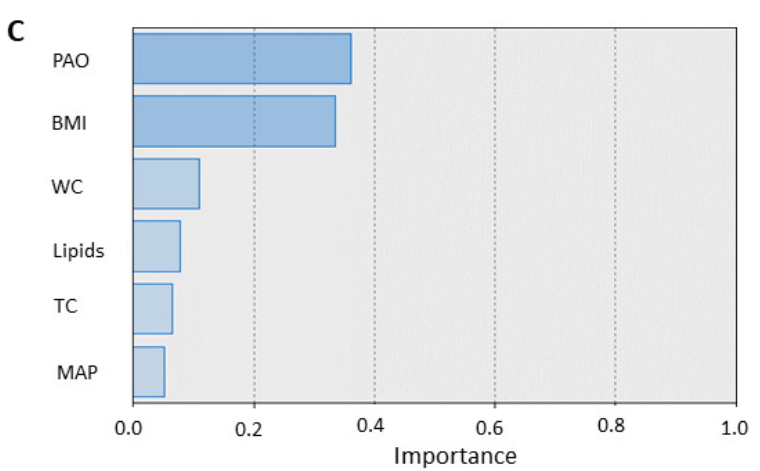

Figure 1. Main predictors for cholesterol (A), for glucose (B), for triglycerides (C).

Finally, the significant Weight Estimation tests weighted per gender are listed in Table 6, showing that for glucose levels the main determinants are carbohydrates, MUFA and Oils; for cholesterol these are MUFA, PUFA and Oils; in third place for LDL the significant variables are proteins, SFA, PAO and sugars; and last, for triglycerides the main variables are BMI, cholesterol and vegetables. When we contrast the same variables weighing per Country, the only difference was found for BMI ( $\mathrm{p} \leq 0.001)$. 
Table 6. Significant Weight Estimation tests weighted per gender

\begin{tabular}{|c|c|c|c|c|c|c|c|}
\hline \multirow{3}{*}{ Variable } & & \multicolumn{4}{|c|}{ Coefficients } & \multirow{3}{*}{$\mathrm{t}$} & \multirow{3}{*}{ Sig. } \\
\hline & & \multicolumn{2}{|c|}{ Non-standardized coefficients } & \multicolumn{2}{|c|}{ Standardized coefficients } & & \\
\hline & & $\mathrm{B}$ & Standard error & Beta & Standard error & & \\
\hline \multirow[t]{4}{*}{ Glucose } & (Constant) & 57.622 & 19.672 & & & 2.929 & 0.005 \\
\hline & $\mathrm{CHOS}$ & 0.03 & 0.011 & 0.28 & 0.105 & 2.663 & 0.01 \\
\hline & MUFA & 0.114 & 0.042 & 0.337 & 0.124 & 2.714 & 0.008 \\
\hline & Oils & -8.117 & 2.91 & -0.337 & 0.121 & -2.789 & 0.007 \\
\hline \multirow[t]{4}{*}{ Cholesterol } & (Constant) & 116.203 & 49.539 & & & 2.346 & 0.022 \\
\hline & MUFA & -0.457 & 0.139 & -0.381 & 0.116 & -3.295 & 0.002 \\
\hline & PUFA & -0.034 & 0.017 & -0.236 & 0.12 & -1.972 & 0.053 \\
\hline & Oils & 24.906 & 8.135 & 0.384 & 0.125 & 3.062 & 0.003 \\
\hline \multirow[t]{5}{*}{ LDL } & (Constant) & 125.963 & 481.508 & & & 0.262 & 0.795 \\
\hline & Proteins & 4.175 & 1.763 & 0.323 & 0.136 & 2.369 & 0.022 \\
\hline & SFA & 6.084 & 2.135 & 0.37 & 0.13 & 2.85 & 0.006 \\
\hline & PAO & -110.572 & 30.294 & -0.458 & 0.126 & -3.65 & 0.001 \\
\hline & Sugars & 152.142 & 62.479 & 0.282 & 0.116 & 2.435 & 0.018 \\
\hline \multirow[t]{4}{*}{$\mathrm{TG}$} & (Constant) & 249.129 & 70.917 & & & 3.513 & 0.001 \\
\hline & BMI & 3.694 & 0.954 & 0.381 & 0.098 & 3.874 & 0 \\
\hline & CHOS & -0.089 & 0.039 & -0.221 & 0.096 & -2.301 & 0.024 \\
\hline & Vegetables & -37.077 & 14.877 & -0.243 & 0.098 & -2.492 & 0.015 \\
\hline
\end{tabular}

CHOS: carbohydrates, BMI: Body Mass Index; LDL: Low-Density Lipoprotein cholesterol, MUFA: MonoUnsaturated Fatty Acids; PAO: Products of Animal Origin, PUFA: PolyUnsaturated fatty acids, SFA: Saturated Fatty Acids, TG: Triglycerides.

\section{DISCUSSION}

CVD involves a complex phenomenon due to numerous causes that may be involved in including of the genetic predisposition and lifestyle, where the latter can be observed as the primary determinant. This is because it can be influenced by assuming a positive or a negative connotation according to each individual [13].

If one takes into consideration BMI values for cardiovascular risk, there is a difference between both populations. For example, in the case of Mexico, the majority of students had malnutrition, while in Colombia, recommended weight-per-age was the constant, with a small percentage with overweight. It should be noted that the socioeconomic context might exert an important influence, in that BMI is considered a weak marker when employed alone as a cardiovascular risk factor. Moreover, BMI is associated with age, not so with body fat; this is in agreement with previous studies in Germany by Bohn et al. and, with respect to Latin America, with a similar population in Argentina [14].

Recently, the relationship of WC with CVD and MetS has been studied in children and adolescents, determining its epidemiological clinical usefulness and notoriety, as it is sufficient to recall that this indicator is a prerequisite for the diagnosis of obesity. In this study, we observed significant figures when we related the WtHR as a cardiovascular risk factor in both populations studied. It is noteworthy that the figures obtained in both
Colombian and Mexican children coincide with other Latin-American references, such as Mederico et al. [8] in Argentina and Chile. This reinforces the idea that it is better to use WtHR and WC in isolation for school population. Our results in this area are also similar to those referred by Cabrera in a study conducted in Cuba in a similar population [15].

$\mathrm{WC} / \mathrm{H}$ is an index with a strong predictive value of cardiovascular risk compared with BMI or WC and even with the percentage of body fat, despite that the potential of this indicator has not been studied in its entirety [4]. There is a direct relationship with lipid profile and even with blood pressure figures. As in similar studies, it was observed that schoolchildren with a WC above the references correlated significantly with high blood pressure (above the 50th percentile for age).

No association was found between lipid profile and anthropometric indicators, except perhaps with that of serum concentrations of TG; despite what was found in the literature and with regard to metabolic alterations, in this study we do not report anything other than hypertriglyceridemia. This could be explained by the sample size and the areas monitored in both countries. Another factor to consider is the positive relationship found between the TG/HDLc index and cardiovascular risk factors, confirming its importance as a clinical sign of damage at the level of tissues and organs. In addition, in the sole study of Di Bonito et al. [16] conducted in Italy, measurement this indicator exceeds the measurements of another type of lipoprotein, with 
the only limitation that in African population, it does not exert the same effect in this study, but where the author has worked exclusively with Latino population, it is entirely valid.

In a previous study with very similar population, González Devia et al. in 2014 [12] observed a positive correlation between atherogenic indices and BMI only for Mexican population; in our case, we found significant figures for both countries. As previously mentioned, both the WHR as well as the WtHR have a clinical interpretation and, combined with the traditional BMI, can enhance a more accurate interpretation of metabolic status in childhood.

With regard to the nutritional aspect in terms of food groups, this is similar for both countries, which was not expected, in that we found in the literature that Latin-American countries have a greater tendency toward greater consumption of vegetables and fruits. However, this is not so in the case of Colombia, where we can clearly observed consumption below the recommendations and one that, of course, also has to do with socioeconomic factors [17]. The fact that the intake of protein is the only one where they have an intake less than the recommended intake may be explained by the cost of meat in both countries resulting from difficult acquisition, and not the amount of carbohydrates that, as reported in the literature, comprises a completely excessive consumption. The latter is directly related with metabolic alterations such as hyperinsulinemia and dyslipidemia.

The ingestion of MUFA influences the serum levels of cholesterol and glucose. This has been previously stated by Park and Lee, both of whom demonstrated that the MUFA to SFA ratio modulates the genetic effects of Glucokinase regulator (GCKR) on serum lipid levels in children [18, 19].

In relation to the effect of Products of Animal Origin (PAO) (equivalents/day), lipids and cholesterol ingestion on the levels of triglycerides, it has been previously proven en several animal models that dietary proteins act synergistically with dietary lipids to regulate cholesterol metabolism, being described that dietary proteins and lipids exerted a separate effect on serum total cholesterol, very low-density lipoprotein cholesterol (VLDL-C), and low-density lipoprotein cholesterol to high density lipoprotein cholesterol (LDL-C/HDL-C) ratio [20, 21].

The clinical picture of physical activity is disheartening when it comes to describing the findings for Mexican population, where the majority of the children were assigned a moderate degree up to null; undoubtedly, the entry of technology and advertising via television or the Internet have exacerbated the situation. Nonetheless, this is not the case in Colombia, where children engage in some type of physical activity more frequently. Despite not performing a physical activity, neither of the two populations had representative numbers of obesity, which is well known as the point of departure in the pathophysiology of CVD. This is important because, despite what has been reported in the most recent national surveys [22, 23], malnutrition and its metabolic alterations continue to comprise a current problem.

This study has some limitations that should be considered. Our sample is not representative of schoolchildren in Mexico and Colombia; therefore, the results cannot be generalized to a larger population. However, the results may be relevant to the extent that the authors have worked with indices of recent integration into the cardiovascular risk profile and by the amount of components discussed in the diet and physical activity, as well as feasibility and practicality for the use of anthropometric and metabolic markers proposed within the daily routine for comprehensive assessment of children-at-risk because they do not always have the opportunity to include biochemical markers due to the high cost of the gaps-in-evidence. Further studies are required to explore afterward both biological and environmental aspects and their effect on the diet as well as on the lipid profile in this age group.

It is important to promote programs and policies at the school level and at home that foster a healthy lifestyle in the school, and it is certainly important to include these as the priority group in terms of the prevention of CVD.

\section{CONCLUSIONS}

1. The use of anthropometric markers such as the WHR and the WtHR, in addition to already known indicators such as BMI and lipid profile, is a useful and accessible tool for the early diagnosis of cardiovascular risk factors in children.

2. This study points out that in children the levels of cholesterol are influenced by the WtHR, MUFA, PUFA, oils and lipids ingestion; glucose levels are influenced by WHR, carbohydrates, MUFA, PUFA, SFA and oils; for triglycerides the main pedictors are PAO, BMI, waist circumference, lipids, cholesterol and vegetables ingestion and MAP.

\section{Conflict of interest}

All of the authors declare that there are no competing interests regarding the publication of this paper.

\section{Acknowledgments}

This work was funded by the Grant 1040/2014RIFC of the UAEMex. The authors appreciate the help of Angela Montenegro-Cárdenas, MSc., in taking the samples. 


\section{REFERENCES}

1. Huang R.C., Prescott S.L., Godfrey K.M., Davis E.A.: Assessment of cardiometabolic risk in children in population studies: underpinning developmental origins of health and disease mother-offspring cohort studies. J Nutr Sci 2015 Apr 10;4:e12. doi: 10.1017/jns.2014.69.

2. Villarreal E., Forero Y., Poveda E., Baracaldo C., López E.: [Cardiovascular risk markers in schoolchildren from five provinces of eastern Colombia]. Biomedica 2008;28(1):38-49 (In Spanish).

3. Savva S.C., Lamnisos D., Kafatos A.G.: Predicting cardiometabolic risk: waist-to-height ratio or BMI. A meta-analysis. Diabetes Metab Syndr Obes 2013;6:403-419. doi: 10.2147/DMSO.S34220.

4. Marrodán M.D., Martínez Álvarez J.R., GonzálezMontero De Espinosa M.L., López Ejeda N., Cabañas M.D., Pacheco J.L., Mesa M.S., Prado C., Carmenate M.M.: [Adiposity assessment from waist to height ratio: prediction equations for Spanish infant population]. Nutr Clin Diet Hosp. 2011;31(3):45-51 (In Spanish).

5. Beck C.C., Lopes Ada S., Pitanga F.J.: Anthropometric indicators as predictors of high blood pressure in adolescents. Arq Bras Cardiol. 2011;96(2):126-133 (In English, Portuguese, Spanish).

6. Anderson L.N., Lebovic G., Hamilton J., Hanley A.J., McCrindle B.W., Maguire J.L., Parkin P.C., Birken C., TARGet Kids Collaboration.: Body mass index, waist circumference, and the clustering of cardiometabolic risk factors in early childhood. Paediatr Perinat Epidemiol. 2016;30(2):160-170. doi: 10.1111/ppe.12268

7. González Devia L.J., Monroy Romero P.A., Almonacid Urrego C.C., Orjuela O.L., Huérfano M.J., Mendieta Zerón $H$. Comparative study of risk factors related to cardiovascular disease in children from Bogotá, Colombia and Toluca, México. Rev Fac Cien Med Univ Nac Cordoba 2014;71(2):98-105.

8. National Institute of Health. The fourth report on the diagnosis, evaluation, and treatment of high blood pressure in children and adolescents. Available at: https://www. nhlbi.nih.gov/files/docs/resources/heart/hbp_ped.pdf

9. WHO. The WHO Child Growth Standards. Available at: http:// http://www.who.int/childgrowth/en/

10. Mederico M., Paoli M., Zerpa Y., Briceño Y., GómezPérez R., Martínez J.L., Camacho N., Cichetti R., Molina Z., Mora Y., Valeri L; Grupo de trabajo CREDEFAR.: Reference values of waist circumference and waist/hip ratio in children and adolescents of Mérida, Venezuela: Comparison with international references. Endocrinol Nutr 2013;60(5):235-242 (In English, Spanish). doi: 10.1016/j.endonu.2012.12.003.

11. ADA. Standards of Medical Care in Diabetes - 2016. Diabetes Care 2016;39(Suppl. 1):S1-S2.

12. Executive Panel on Detection Evaluation and Treatment of High Blood Cholesterol in Adults. Executive Summary of the Third Report of the National Cholesterol Education Program (NCEP) Expert Panel on Detection, Evaluation, and Treatment of High Blood
Cholesterol in Adults (Adult Treatment Panel III). JAMA. 2001;285(19):2486-2497.

13. Sánchez-Contreras M., Moreno-Gómez G.A., MarínGrisales M.E., García-Ortiz L.H.: Cardiovascular risk factors in young people. Rev Salud Publica (Bogota). 2009;11(1):110-122 (In Spanish).

14. Piazza N. [Waist circumference in children and adolescents]. Arch Argent Pediatr. 2005;103:5-6 (In Spanish).

15. Cabrera-Rode E., Bioti Torres Y., Marichal Madrazo S., Parlá Sardiñas J., Arranz Calzado C., Olano Justiniani R., González Fernández P., Vera González M.: [Waisthip index versus waist circumference for the diagnosis of metabolic syndrome in children and adolescents with first-degree relatives with type 1 diabetes]. Rev Cubana Endocrinol 2011;22(3):182-195 (In Spanish).

16. Di Bonito P., Valerio G., Grugni G., Licenziati M.R., Maffeis C., Manco M., Miraglia del Giudice E., Pacifico L., Pellegrin M.C., Tomat M., Baroni M.G.: CARdiometabolic risk factors in overweight and obese children in ITALY (CARITALY) Study Group. Comparison of non-HDLcholesterol versus triglycerides-to-HDL-cholesterol ratio in relation to cardiometabolic risk factors and preclinical organ damage in overweight/obese children: The CARITALY study. Nutr Metab Cardiovasc Dis. 2015;25(5):489494. doi: 10.1016/j.numecd.2015.01.012.

17. Alayón A.N., Castro-Orozco R., Gaviria-Esquivia L., Fernández-Franco M., Benitez-Peña L.: [Cardiovascular risk factors among 7-and 14-year old schoolchildren in Cartagena, Colombia, 2009]. Rev Salud Publica (Bogota). 2011;13(2):196-206 (In Spanish).

18. Park J.Y., Lee H.J., Jang H.B., Hwang J.Y., Kang J.H., Han B.G., Lee J.Y., Song J. Interactions between ADIPOQ gene variants and dietary monounsaturated: saturated fatty acid ratio on serum lipid levels in Korean children. Nutr Metab Cardiovasc Dis. 2014;24(1):8390. doi: 10.1016/j.numecd.2013.04.007.

19. Lee H.J., Jang H.B., Kim H.J., Ahn Y., Hong K.W., Cho S.B., Kang J.H., Park S.I.: The dietary monounsaturated to saturated fatty acid ratio modulates the genetic effects of GCKR on serum lipid levels in children. Clin Chim Acta. 2015;450:155-161. doi: 10.1016/j.cca.2015.08.012

20. Bergeron N., Deshaies Y., Lavigne C., Jacques H.: Interaction between dietary proteins and lipids in the regulation of serum and liver lipids in the rabbit. Effect of fish protein. Lipids. 1991;26(9):759-64.

21. Bergeron N., Deshaies Y., Jacques H.: Factorial experiment to determine influence of fish protein and fish oil on serum and liver lipids in rabbits. Nutrition. 1992;8(5):354-8.

22. Profamilia. [National demographic and health survey (ENDS 2010)]. Available at: https://pdf.usaid.gov/pdf_ docs/Pnady407.pdf

23. Instituto Nacional de Salud Pública. [2012 National Health and Nutrition Survey]. Available at: https:// ensanut.insp.mx/index.php\#.WMqj6NThC9I

Received: 27.06.2017

Accepted: 05.02.2019

This article is available in Open Access model and licensed under a Creative Commons Attribution-Non Commercial 3.0.Poland License (CC-BY-NC) available at: http://creativecommons.org/licenses/by-nc/3.0/pl/deed.en 